\title{
Millennium Development Goals: background
}

\author{
Mickey Chopra, ${ }^{1}$ Elizabeth Mason ${ }^{2}$
}

${ }^{1}$ UNICEF
${ }^{2}$ Institute for Global Health,
University College, London, UK

Correspondence to

UNICEF, 42rd Avenue, 2nd

Street, New York, New York, USA. mchopra@unicef.org or

Dr Elizabeth Mason, Institute for Global Health, University

College London, 30 Guildford St,

London WC1N 1EH;

elizabeth.mason@ucl.ac.uk

Received 6 November 2014 Accepted 14 November 2014

CrossMark

To cite: Chopra M,

Mason E. Arch Dis Child

2015:100(Suppl 1):s2-s4.

\section{INTRODUCTION}

The Millennium Development Goals (MDG) arose from one of the largest ever gathering of world leaders in New York in September 2000. ${ }^{1}$ Collectively, 189 countries adopted the United Nations Millennium Declaration, which evolved into the MDG. ${ }^{2}$ These ambitious targets-ranging from halving extreme poverty and reducing maternal mortality by three-quarters to achieving universal primary schooling and halting (and beginning to reverse) the spread of HIV/AIDS-are supposed to be met by the end of 2015 .

The Millennium Declaration represented an important break with previous efforts to rally the world around global development. The articulation of specific goals and targets with a heavy focus on social development such as education, health, nutrition and water and sanitation was a distinctive move away from the monolithic focus upon macroeconomic growth. The setting of goals and targets and the establishment of monitoring and accountability frameworks was another important shift.

The process of formulating the MDG must be seen in the context of widespread criticism of the United Nations (UN) during the two decades prior to 2000. The lack of a common development framework alongside declining global aid-for example, the foreign aid budget of the USA hit an all-time low in 1997, at $0.09 \%$ of gross national income-allowed global financial institutions such as the World Bank and International Monetary Fund to dominate development priorities. Not surprisingly, given the ruling paradigm of achieving economic growth by cutting social expenditures and reducing the role of the state, there was insufficient progress in reducing preventable child deaths, especially for those countries in Africa, South Asia and Latin America.

There remains an active debate as to what extent the setting of a limited number of goals and targets has helped or hindered broad and inclusive development across the world. A study by Charles Kenny and Andy Sumner ${ }^{3}$ suggests that the MDG boosted aid flows and redirected them towards smaller, poorer countries and towards targeted areas such as education and public health. There is good evidence that this has translated in many parts of the world into accelerated progress. Particularly important have been the access to free primary education and free healthcare for children aged $<5$ years and pregnant women in many low-income countries. Perhaps, the greatest MDG successes concern health especially the progress made in reducing child mortality (MDG 4) and HIV/AIDS, malaria and tuberculosis (TB) (MDG 6) and more latterly maternal mortality (MDG 5a). ${ }^{4}$ The MDG formed the basis for the formation of multilateral global health institutions, such as the GAVI Alliance and Global Fund for HIV/AIDS, malaria and TB. The private sector plays a central part in both the institutions with representation at the Board level, active engagement in the governance committees and collaboration in implementation-another clear break with previous paradigms that had tended to ignore the role of the private sector in social development.

The combined results have been remarkable. For example, the most recent UN report on levels and trends in child mortality ${ }^{5}$ documents the almost halving of child mortality rates since 1990, dropping from 90 to 46 deaths per 1000 live births in 2013. The absolute number of under-five deaths was cut in half during the same period, from 12.7 million to 6.3 million, saving 17000 lives every day. Furthermore, the under-five mortality is falling faster than at any other time during the past two decades. Globally, the annual rate of reduction has more than tripled since the early 1990s. Eastern and Southern Africa currently has the highest annual rate of reduction in the world with the exception of East Asia and the Pacific. Analysis undertaken in the 2014 'A Promise Renewed' report $^{6}$ shows that in sub-Saharan Africa, a continent that the MDG were meant to draw focus upon, more than $90 \%$ of countries have seen the decline in child deaths accelerate compared with 1996-2001. Nonetheless, there remains wide inequities within countries, particularly the urban-rural divide with studies demonstrating that the poorer quintiles of the population have less access to healthcare services and higher mortality rates. ${ }^{7}$

Of course one question that immediately arises is how much of this would have been achieved even without the MDG process? In a recent analysis, Baker $^{8}$ creates a counterfactual of progress in reductions in child mortality rates continuing at the same rate as the 10 years before the Millennium Declaration in 2000. He finds that if the trend for the whole of the 1990s is extrapolated to 2013, $8.2 \mathrm{~m}$ children aged $<5$ years would have died globally last year; the cumulative total of lives 'saved' since 2001 is $13.6 \mathrm{~m}$. These findings do not prove that setting the MDG caused child deaths to fall, merely that something improved in the years that followed, nor does the fact that the biggest improvements came in poorer countries that were the main focus of MDG-inspired policies, lobbying, education and aid. Perhaps all this would have happened anyway. As the Economist concludes, 'On balance though, there is good circumstantial evidence that setting the child-mortality MDG helped save millions of young lives.'

Success of course is variable, both across the different MDG, across different countries and within countries. What have we learnt about success? One measure of success is the commitments both 
financial and otherwise, towards the achievement of the MDG. In 2010, the UN Secretary General Secretary General launched the Global Strategy for Women's and Children's Health ${ }^{9}$ to spearhead acceleration of progress towards MDG 4 and 5 which were at the time seen to be lagging behind in progress. There were immediately 111 commitments worth $\$ 40$ billion from lowincome and high-income governments, non-governmental organisations, UN agencies, the private sector and others. The Partnership for Maternal, Newborn and Child Health 2014 report ${ }^{10}$ tracking these commitments showed that by May 2014, these had increased to 300 commitments worth almost $\$ 60$ billion. A closer look reveals that the amount shrinks to $\$ 45$ billion, once double counting is removed, and a real additional amount of $\$ 22$ billion, of which $\$ 13-17$ billion is aimed at the 49 lowest income countries, far short of the $\$ 88$ billion gap highlighted in the Global Strategy. ${ }^{11}$ The report also highlights the important influence of the Global Strategy on international donor spending and an increase in the rate of disbursements; in addition, non-financial commitments would booster the total amount available for $\mathrm{MNCH}$. Furthermore, the report also highlights great variance in financial commitments between countries, an increase in domestic spending of $15 \%$ for the 49 poorest and $21 \%$ for the 75 Countdown countries, and great variation in Overseas Development Assistance spending versus levels of maternal and child mortality. Financial success measured at a macro level can and does suppress the between and within country differences, nevertheless, taken as a whole demonstrates positive trending. Another is coverage, Countdown to 2015 $\mathrm{MNCH}^{12}$ monitors coverage of key interventions for maternal, newborn and child health, disaggregates coverage by wealth quintile and models lives saved related to coverage of interventions. Similarly, coverage of HIV-positive people with anti retroviral treatment therapy and coverage of bed nets to prevent malaria and the focus of key monitoring efforts with rapid advances in coverage as the result of targets and advocacy demonstrating the possibility of success. ${ }^{13}$

\section{WHAT HAVE WE LEARNT ABOUT THEIR SHORTCOMINGS?}

Although there is a growing consensus that the MDGs were successful in focusing attention on important development goals and promoting a culture of monitoring and accountability, there were important limitations. First, there was the relatively narrow range of developmental outcomes that were selected. For example, the focus of education on primary school enrolment came at the expense of retention of children (especially girls) in school and the quality of education. Within health, the MDG omitted important conditions such as non-communicable diseases, mental health, injuries and adolescent health. The MDG also did not consider disability (despite 15\% of the world's people living with some form of disability).

Second, the strength of the MDG in focusing on specific targets may have come at the expense of encouraging a vertical focus around individual goals and targets. Some commentators have expressed a concern that this has sometimes led to a fragmented approach whereby sectors focused on their 'own' goal, and interests within sectors organised around particular targets. For example, poor hygiene behaviours and water and sanitation facilities in healthcare facilities have been recognised as an important factor in persistent high levels of maternal mortality and morbidity; however, surveys consistently show little improvement despite separate MDG related to water and sanitation and to maternal mortality. ${ }^{14}$ Also there is an assumption that as MDG 4 and 5 focused on women and children, all their needs were covered. In reality, family planning was neglected until 2012, with the Family Planning London Summit held in July 2012 and the launch of FP2020. ${ }^{15}$ Newborn health has been even more neglected with no specific MDG target, and the slow rate of decline in mortality only being redressed with the adoption of the Every Newborn: An action plan to end preventable deaths by the World Health Assembly in May 2014. ${ }^{16}$

Third, the goals only stated overall progress and did not specify reductions in inequity.

Subsequent modelling by Gwatkin ${ }^{17}$ showed that many countries could achieve the goals by increasing the disparities between the richest and the poorest. Early analysis did suggest that many of the countries making the greatest progress in reducing child mortality did so at the expense of the poorest quintile in these countries (Wardlow et $\mathrm{al}^{18}$ ). However, more recent analysis of the fastest improving countries has shown that they have made this progress by focusing on the poorest (Victora and Barros ${ }^{19}$ ). The health MDG were also expressed as a proportional reduction in rates (ie, countries to achieve a three-quarter reduction in child mortality), countries starting with high baseline rates in 1990 could achieve the MDG and yet still remain with a high rate of mortality, notably significantly higher than other countries.

The post-2015 development agenda calls for a better understanding and linkage of the role of health with respect to other societal goals. Continuing to miss the opportunity to highlight these health issues, which have significant impacts on well-being and development, is no longer an option. At the same time, the health impacts of emerging challenges such as urbanisation, ageing, increasing commodification of healthcare and climate change will need to be addressed in any new health goals. The call for goals that lead to ending preventable maternal, newborn, child and adolescent deaths ${ }^{20}$ could be the impetus needed to address the social determinants of health, human rights as well as the health interventions required to achieve these far-reaching targets. They require a far greater focus on equity and would not allow the 'outliers' to continue to be neglected.

Perhaps, the most important lesson from the MDG that we need to take forward is the close interaction between health and the broader social determinants. The post-2015 rearticulation of development goals provides a critical opportunity to place health as an outcome of each of the three dimensions of sustainable development: inclusive economic development, inclusive social development and environmental sustainability. We have a short window within which to more clearly outline the nature of these relationships and hence identify specific metrics to monitor and eventually hold stakeholders accountable for real changes to peoples' lives. Doing so will require a better understanding, and implementation, of social determinants and human rights approaches and developing goals and targets to reflect this integration.

\section{Competing interests None.}

Provenance and peer review Commissioned; internally peer reviewed.

\section{REFERENCES}

1 United Nations Millennium Declaration. Resolution 55/2 adopted by the General Assembly. 8 September 2000

2 http://www.un.org/millenniumgoals/

3 Kenny C, Sumner A. More Money or More Development: What have the MDGs achieved? Working paper 278. Centre for Global Development, December 2011.

4 The Millennium Development Goals Report 2014

5 Levels and Trends in Child Mortality, Report 20014. Estimates developed by the UN interagency Group for Child Mortality Estimation.

6 Committing to Child Survival: A Promise Renewed. Progress Report 2014, UNICEF.

7 Barros AJ, Victora CG Measuring coverage in, MNCH: determining and interpreting inequalities in coverage of maternal, newborn and child health interventions. PLOS Med 2013;10:e1001390. 
8 Baker-Falling Child Mortality: the causes of a welcome trend. The Economist October 2014.

9 Global Strategy for Women's and Children's Health. UN SG Ban Ki-moon. http:/l www.who.int/pmnch/topics/maternal/20100914_gswch_en.pdf?ua+1

10 The PMNCH Accountability 2014 Report. Tracking financial commitments to the Global Strategy for Women's and Children's Health. PMNCH, WHO 2013.

11 The MNH funding gap is a subset of the US\$88 billion funding gap for women's and children's health. See: Global Strategy Finance Working Group. Background paper for the Global Strategy for Women's and Children's Health: financial estimates in the Global Strategy. New York, United Nations, 2010.

12 Requejo JH, Bryce J, Barros AJ, et al. Countdown to 2015 and beyond: fulfilling the health agenda for women and children. Lancet 2014. Pii S0140-6736(14)60925-9.

13 Fulfilling the Health Agenda for Women and Children: The 2014 report. Countdown to 2015, Maternal, Newborn and Child Survival. UNICEF and WHO 2014. Global Update on the Health Sector Response to HIV, 2014. WHO 2014.
142014 Every Woman Every Child: a Post 2015 vision. The third Report of the independent Expert Review Group on Information and Accountability for Women's and Children's Health. WHO 2014.

15 http://www.gov.uk/.../news/family-planning-london-summit-11-july-2012

16 Every Newborn: An Action Plan to End Preventable Deaths. WHO June 2014.

17 Gwatkin, DR. 2002. Who would gain most from efforts to reach the millennium development goals for health? An inquiry into the possibility of progress that fails to reach the poor. Washington DC: World Bank, http:/hdl.handle.net/10986/13693

18 Wardlow T, You D, Anthony D, et al. Child survival: a message of hope but a call for renewed commitment in UNICEF report. Reprod Health 2013;10:64.

19 Victora CG, Barros AJ. Socioeconomic inequalities in neonatal mortality are falling: but why? Lancet Global Health 2014;2:e 122-3.

202014 Every Woman Every Child: A Post 2015 vision. The third Report of the independent Expert Review Group on Information and Accountability for Women's and Children's Health. WHO 2014. 